\title{
Recycling and application of expired desloratadine medicinal drugs for inhibition of steel corrosion in acid environment: Analytical studies
}

\author{
R.S. Abdel Hameed, ${ }^{1,2}{ }^{\circledR} *$ M.T. Qureshi, ${ }^{1}$ D. Mohamed, ${ }^{1}$ M. Abdallah, ${ }^{3}$ \\ E.H. Aljuhani, ${ }^{3}$ M.M. Aljohani, ${ }^{4}$ M.S. Soliman ${ }^{5}$ and S.R. Al-Mhyawi \\ ${ }^{1}$ Basic Science Department, Preparatory Year, University of Ha'il, 1560, Hail, KSA \\ ${ }^{2}$ Chemistry Department, Faculty of Science, Al-Azhar University,11884, Cairo, Egypt \\ ${ }^{3}$ Chemistry Department, Faculty of Science, Umm Al-Qura University, Makkah \\ Mukaramha, KSA \\ ${ }^{4}$ Department of Chemistry, Faculty of Science, University of Tabuk, Tabuk 71491, KSA \\ ${ }^{5}$ Department of Pharmaceutics, Faculty of Pharmacy, University of Ha'il, 1560, Hail, KSA \\ ${ }^{6}$ Chemistry Department, College of Science, University of Jeddah, Jeddah 22233, Saudi \\ Arabia \\ *E-mail: mredars2@yahoo.com
}

\begin{abstract}
Desloratadine medicinal drug tablets known as Clarinex is a complex formulation comprising desloratadine, excipients, and a coating. It is a famous antihistamine used only for adult patients. It is dangerous to be left in the environment after its expiration as it is harmful to children. So, the present work introduces the idea of using Desloratadine tablets in expired form as green corrosion inhibitors for steel in $1.0 \mathrm{~N} \mathrm{HCl}$. Five analytical techniques were used to evaluate the inhibition performance of expired Desloratadine drug, namely gravimetric, atomic absorption spectroscopy (AAS), thermometric, gasometric, and acidimetric techniques. The effect of expired drug concentration, reaction temperature, and $\mathrm{pH}$ was studied. Corrosion inhibition was found to increase with an increase in concentration and to decrease with rising temperature and a decrease in $\mathrm{pH}$. The techniques used are in good agreement with each other $( \pm 2 \%)$ indicating that it is possible to use the expired Desloratadine drug as a potential nontoxic green corrosion inhibitor for steel in industrial field at low $\mathrm{pH}$ values.
\end{abstract}

Received: October 31, 2021. Published: December 20, 2021

doi: $10.17675 / 2305-6894-2021-10-4-24$

Keywords: expired drugs, green inhibitors, gravimetric, thermometric, AAS, acidimetric.

\section{Introduction}

Generally, drugs are one of the most famous chemical materials of everyday and continuous use in our homes. Expired drugs considered as dangerous materials in the environment cause the death of more than 2000 children every year. In some countries the expired drugs were wasted into holes in a desert leading to pollution of underground waters by harmful materials. All these observations have taken the attention of Reda Abdel Hameed to search 
for new applications for expired drugs. The use of expired drugs as corrosion inhibitors for metals was introduced by Reda Abdel Hameed in 2009 and 2011 [1,2]. When he used expired ranitidine drug as an eco-friendly potential non-toxic corrosion inhibitor for aluminum in hydrochloric acid solution, his work took the attention of other scientists who then investigated many expired drugs as corrosion inhibitors. Further, the research of unused drugs has been focused on corrosion inhibition of carbon steel in various aggressive media [3-12]. In the past decade, scientific efforts in the field of corrosion inhibition were focused on eco-friendly and potential non-toxic corrosion inhibitors known as green corrosion inhibitors. The most recent efforts involve the use of expired drugs to solve not only the problem of solid waste accumulation but also to introduce a potential nontoxic inhibitor, save energy, money consumed in preparing or sailing a chemical corrosion inhibitor. About $7 \%$ of the total income is consumed in the corrosion inhibition of metals and alloys in industrial fields [1-8].

From a green chemistry point of view, the use of expired drugs materials as inhibitors help in the following points:

1) Avoid the toxic effect of some toxic inhibitors on humans,

2) Using drugs saves the energy and organic solvents utilized in the synthesis of corrosion inhibitors,

3) There are no waste materials if drugs are used as inhibitors; in addition,

4) Avoiding the accumulation of drug wastes that are dangerous for children and ground waters.

From the previous points, expired drugs are considered as green inhibitors, because there is no waste from the process of using drugs as inhibitors as they are taken directly from the drug market to the laboratory, where they are used in their pharmacological form which is safe for humans and the environment in very small doses. In addition, corrosion is the process of oxidation of metals by its environment leading to corrosion products and destruction of the metal lattice. This phenomenon represents a terrible waste of both natural resources and money so the corrosion control of steel is of technical, economical, and environmental importance. When steel is corroded, it changes from a hard and useful metal into a corrosion product which is a hazard to the environment so the corrosion control of steel is considered a green process, too. The damage by corrosion results in high costs for maintenance and protection of the materials used. Finally, the expired drug is considered a green inhibitor as it is nontoxic inhibitor to humans, especially at very low concentrations. In the previous works $[13,14]$ expired paracetamol and expired Indomethacin were used as corrosion inhibitors for steel in an acid and sodium chloride corrosive environment using chemical and electrochemical techniques. Analytical and electroanalytical techniques are highly effective and widely used for the evaluation of large numbers of materials as corrosion inhibitors for metals and alloys in many different aqueous corrosive environments [15-30] containing acids, alkaline, and aqueous salts [33-50]. In the present work five different analytical techniques were used to evaluate expired Desloratadine drug as a green corrosion 
inhibitor for steel in $1.0 \mathrm{~N}$ hydrochloric acid corrosive environment. The effect of expired drug concentration, reaction temperature, and $\mathrm{pH}$ on the corrosion inhibition efficiency were studied. Desloratadine medicinal drug is a famous antihistamine. It is a long-acting piperidine derivate with selective $\mathrm{H} 1$ anti-histaminergic and non-sedating properties $[31,32]$. The Desloratadine medicinal drug is widespread in our homes. It has beautiful shape and color which makes it more attractive for children, so it is so dangerous to be left in the environment after its expired as it is harmful to children. A literature survey shows that Desloratadine is used to provide symptomatic relief of allergic symptoms. Desloratadine is loratadine in which the ethoxycarbonyl group attached to the piperidine ring is replaced by hydrogen. The major metabolite of loratadine, desloratadine, is an antihistamine that is used for the symptomatic relief of allergic conditions including rhinitis and chronic urticaria. It does not readily enter the central nervous system, so does not cause drowsiness. It has a role as an H1-receptor antagonist, an anti-allergic agent, and a cholinergic antagonist $[31,32]$. Each tablet contains $5 \mathrm{mg}$ Desloratidine in addition to excipients: cellulose microcrystalline, partially pregelatinized maize starch, magnesium citrate, silica colloidal anhydrous. The coating contains Opadry blue 03A30735 (hypromellose $6 \mathrm{cP}$ ), titanium dioxide, microcrystalline cellulose, stearic acid, and indigotin carmine. All these components are rich with functional groups. From the literature, we can conclude that the expired Desloratadine drug is highly promising as a corrosion inhibitor for steel in acid environments.

\section{Experimental}

\subsection{Materials and test solution}

The corrosive solution used in this study was aggressive $1.0 \mathrm{~N}$ hydrochloric acid with $\mathrm{pH}$ 0.0 which was prepared from analytical grade $37 \% \mathrm{HCl}$ (Sigma Aldrich) by dilution with double-distilled water and titrated against $1.0 \mathrm{~N} \mathrm{Na}_{2} \mathrm{CO}_{3}$, then diluted to the appropriate required $\mathrm{pH}$. Each experiment was performed in aerated stagnant solutions and was repeated at least three times under the same conditions to check the reproducibility. The average of the three replicated values was used for further data processing. The gravimetric composition of the steel material employed in this study is given in Table 1. It is similar to the composition of the carbon steel used in the manufacturing of petroleum pipelines.

Table 1. Gravimetric composition of the steel material used.

\begin{tabular}{ccccccc}
\hline Element & Mn & Si & S & P & C & Fe \\
\hline Content (weight \%) & 0.518 & 0.202 & 0.008 & 0.008 & 0.16 & About 99\% \\
\hline
\end{tabular}

Desloratadine tablets were taken from our home after the expired date by 6 months, as a product of Genepharm S. A. company, Greece. The drug tablets were crushed to a powder, which was then heated with alcohol for $5 \mathrm{~h}$ under reflux. The mixture was cooled to room 
temperature and allowed to settle. The solution was filtered, and the filtrate was allowed to dry to yield a soluble colloidal extract. The colloidal filtrate was used as a green corrosion inhibitor for steel in the present study. Its chemical structure and composition are given in Figure 1.

\subsection{Gravimetric studies}

The gravimetric method is widely used because it has the advantage of being simple and does not require complex equipment or procedures. All the experiments were done three times and the recorded data was taken to the mean value with $( \pm 0.1)$ error. In this study, two types of gravimetric tests were carried out, namely the weight loss measurement and determination of the metal concentration passed into solution by atomic absorption spectroscopy.

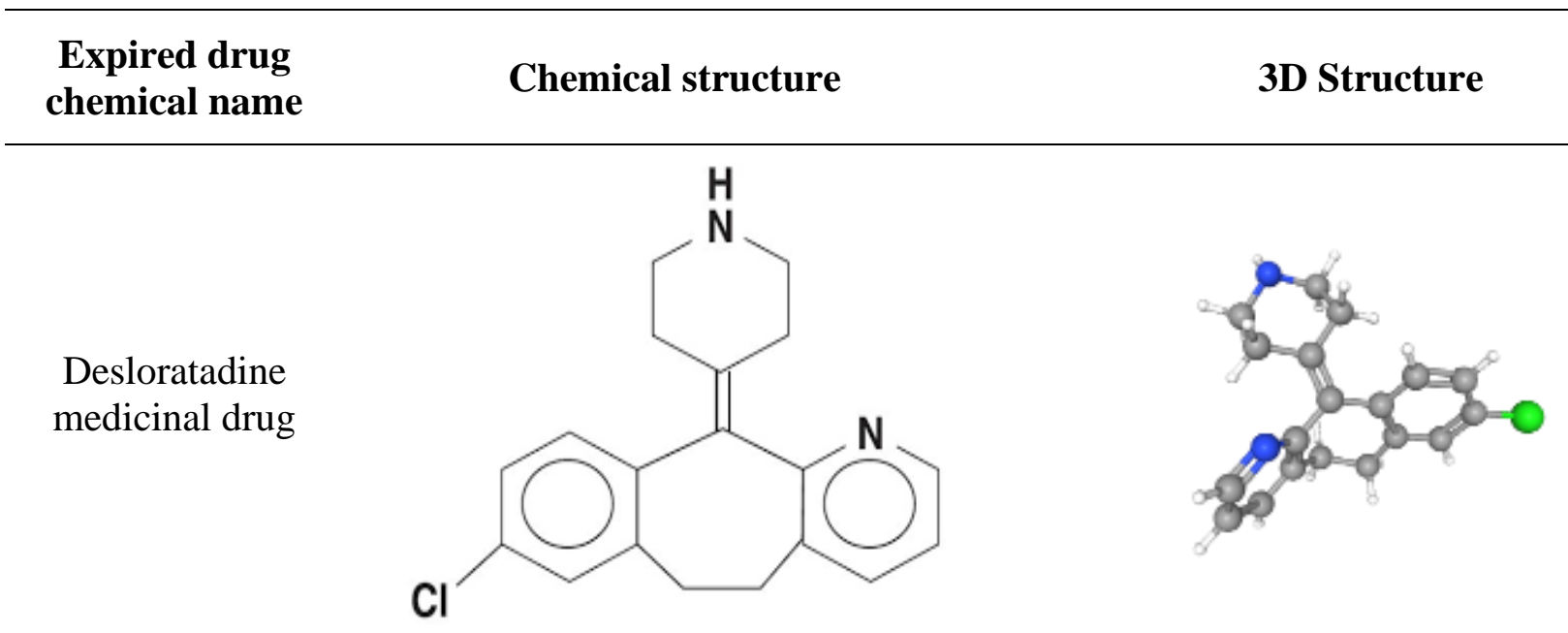

Figure 1. 3D and chemical structural formulas of Desloratadine drug which used as an inhibitor.

\subsubsection{Weight loss measurement}

The technique is based on determining the weight loss (WL) of a sample (coupon) with surface $(S)$ immersed for a time $(t)$ in the aggressive solution. The tests are performed in $100 \mathrm{~mL}$ glass vials in a non-aerated medium, at room temperature. The immersion time is $8 \mathrm{~h}$. Iron samples undergo cleaning with distilled water, degreasing with acetone, and drying before and after the immersion. The corrosion rate $W$ was determined by the following relationship (1):

$$
W=\frac{m_{\mathrm{i}}-m_{\mathrm{f}}}{S t}
$$

where $W\left(\mathrm{mg} \cdot \mathrm{cm}^{-2} \cdot \mathrm{h}^{-1}\right)$ is the corrosion rate, $m_{\mathrm{i}}(\mathrm{mg})$ and $m_{\mathrm{f}}(\mathrm{mg})$ are the masses before and after exposure to the test solution, respectively, $S\left(\mathrm{~cm}^{2}\right)$ is the surface area of the specimen, and $t(\mathrm{~h})$ is the immersion time. The inhibitory efficiency I.E.\% and the surface coverage $(\theta)$, 
which represents the part of the metal surface covered by the inhibitor molecules, were calculated according to the following equations [26-29]:

$$
\begin{aligned}
\text { I.E. } \% & =\left(\left[W^{0}-W\right] / W^{0}\right) \cdot 100 \\
\theta & =\left(\left[W^{0}-W\right] / W^{0}\right)
\end{aligned}
$$

where $W^{0}$ and $W$ represent the corrosion rates in the absence and in the presence of the inhibitor, respectively.

\subsubsection{Atomic absorption spectroscopy (AAS) measurements}

The content of iron ions in corrosive solutions in the absence and presence of the drug used as a corrosion inhibitor was determined by atomic absorption spectroscopy (AAS). The concentration of ferric ions passed into the solution was performed using a Varian Spectra AA 220 atomic absorption spectroscopy instrument. To determine the concentrations of iron ions within a corrosive solution both when the inhibitor was absent and present, we diluted the corrosive medium with aqua regia $[13,42]$.

\subsection{Gasometrical measurements (hydrogen evolution measurements)}

The progress of the corrosion reaction was determined by volumetric measurement of the evolved hydrogen. The metal sample was put in a Büchner flask containing the test solution. The flask was sealed with a rubber bung, and from its hose barb protruding from its neck, rubber tubing was connected to the bottom of an inverted measuring cylinder which was fitted above a basin. The cylinder and the basin were filled with distilled water. The evolved hydrogen gradually displaces distilled water and is collected at the top inside the cylinder, and its volume is measured directly with time [13, 42]. The experiment is done in the absence and presence of different concentrations of the tested inhibitor.

\subsection{Thermometric measurements}

A carbon steel sheet with a chemical composition indicated in Table 1 was press cut to $2 \times 2 \times 0.1 \mathrm{~cm}$ dimensions. The measurements were carried out in a Dolvacpyrex flask covered with a sheet of aluminum foil. The reaction vessel consists of $50 \mathrm{~mL}$ of the acid test solution put into the flask covered with sheets of aluminum foil, corked with a Check temp digital thermometer in place. The metal coupon was introduced into the corrosive solution and quickly covered. Thermometric measurements depend on measuring the temperature variation during the reaction of a metal with a test piece with a definite volume of a corroding solution [13]. The variation of temperature of the system with time was monitored and the reaction number $(R N)$ was defined as $[13,42]$

$$
R N\left({ }^{\circ} \mathrm{C} / \mathrm{min} .\right)=\left(T_{\mathrm{m}}-T_{\mathrm{i}}\right) / t_{\mathrm{m}}
$$

Where $T_{\mathrm{m}}$ and $T_{\mathrm{i}}$ are the maximum and initial temperature, respectively, and $t_{\mathrm{m}}$ is the time in minutes taken to attain the maximum temperature. 


\subsection{Acidimetric Measurements}

Each experiment was preceded by an evaluation for the $\mathrm{pH}$ of the prepared solution by a standard BT-500 model $\mathrm{pH}$ meter (Germany). The $\mathrm{pH}$ was checked for the five concentrations of 400, 800,1200, 1600, and 2000 ppm pre and post exposure in the checked solution for $7 \mathrm{hrs}$. The I.E.\% value was computed by the following equation:

$$
\text { I.E. } \%=1-\left(\left[\Delta \mathrm{H}^{+}\right]_{\text {inh. }} /\left[\Delta \mathrm{H}^{+}\right]_{\text {uninh. }}\right) \cdot 100
$$

Where $\left[\Delta \mathrm{H}^{+}\right]_{\text {inh. }}$ and $\left[\Delta \mathrm{H}^{+}\right]_{\text {uninh. }}$ are changes in $\mathrm{H}^{+}$concentration with and without the inhibitor, respectively $[13,42]$.

\section{Results and Discussion}

Simple analytical techniques were used to estimate the corrosion rate and determine the ferrous ion concentration in the presence and absence of Desloratadine drug as a green corrosion inhibitor in an acidic $1.0 \mathrm{~N} \mathrm{HCl}$ solution. In the present research, the effect of inhibitor concentration, $\mathrm{pH}$, and temperature was studied. The gravimetric, thermometric, gasometrical, acidimetric, and atomic absorption spectroscopy (AAS) were used in this study as analytical techniques. The Desloratadine drug used as a green inhibitor is symbolized here as Desloratadine. Concentrations of 400, 800, 1200, 1600, and 2000 ppm were studied.

\subsection{Gravimetric measurements}

\subsubsection{Effect of concentration}

Gravimetric techniques were used to determine the corrosion rate and corrosion inhibition efficiency I.E.\% of expired desloratadine drug for various concentrations of Desloratadine inhibitor after 7 hours of immersion of steel coupons in the hydrochloric acid corrosive environment with different $\mathrm{pH}$ values $(\mathrm{pH} 1,2$, and 3$)$. The values of corrosion rate $(W)$ and corrosion inhibition efficiency I.E.\% are given in Table 2 and Figure 2. According to gravimetric results, the weight loss and consequently the corrosion rate decrease and inhibition efficiency increases upon addition of expired Desloratadine drug green inhibitor and this behavior was increased as the Desloratadine inhibitor concentration was increased. It's clear that the inhibition efficiency increases as the inhibitor concentration increases to attain $98 \%$ at $300 \mathrm{ppm}$. The inhibitory efficiency I.E.\% and the surface coverage $(\theta)$, which represents the fraction of the metal surface covered by the inhibitor molecules, were calculated according to equations 2 and 3 mentioned in the Experimental part. Inspection of Table 2 reveals that the values of inhibition efficiency increase with increasing concentration of the drug and decrease with a decrease in the medium $\mathrm{pH}$. Figure 2 reveals that on increasing the concentration of expired Desloratadine drug, the weight loss of carbon steel samples is reduced, indicating that the presence of these compounds lowered the dissolution of iron in $1.0 \mathrm{~N} \mathrm{HCl}$ solution. This observation indicates that these drugs act as inhibitors due to the blocking effect of the drug materials on the metal surface's active sites. The variation of weight loss with time in uninhibited and inhibited $1.0 \mathrm{~N} \mathrm{HCl}$ is linear. This 
illustrates the absence of insoluble surface films during corrosion. In this case, the inhibitors are first adsorbed onto the metal surface and thereafter impede corrosion either by merely blocking the reaction sites (anodic and cathodic) or by altering the mechanism of the anodic and cathodic partial processes [26-29]. The maximum inhibition efficiency obtained using $2000 \mathrm{ppm}$ of expired Desloratadine drugs is $98 \%$ which is higher than the efficiency obtained in the cited references (previous works) [13,42]. This observation may be due to the small amount of potassium iodide present as an additive in the Desloratadine drug which acts as a promoter for organic drug molecules: as mentioned elsewhere [26-29], the presence of inorganic salts has a synergistic effect on the corrosion inhibition efficiency.

Table 2. Effect of concentration of the expired drug on the corrosion parameters of steel in $\mathrm{HCl}$ solution with different $\mathrm{pH}$ values obtained from the weight loss measurements at $303 \mathrm{~K}$.

\begin{tabular}{ccccccc}
\hline \multirow{2}{*}{$\begin{array}{c}\text { Expired drug } \\
\text { concentration, } \\
\mathbf{p p m}\end{array}$} & \multicolumn{2}{c}{$\mathbf{p H}=\mathbf{1}$} & \multicolumn{3}{c}{$\mathbf{p H}=\mathbf{2}$} & \multicolumn{2}{c}{$\mathbf{p H}=\mathbf{3}$} \\
\cline { 2 - 7 } & $\mathbf{I . E . \%}$ & $\mathbf{\theta}$ & I.E.\% & $\boldsymbol{\theta}$ & I.E.\% & $\boldsymbol{\theta}$ \\
\hline 0 & - & - & - & - & - & - \\
400 & 87.5 & 0.875 & 88.6 & 0.886 & 90.1 & 0.901 \\
800 & 89.7 & 0.897 & 90 & 0.9 & 91.8 & 0.918 \\
1200 & 90.5 & 0.905 & 93.5 & 0.935 & 95.5 & 0.955 \\
1600 & 91.8 & 0.917 & 94.5 & 0.945 & 95.2 & 0.952 \\
2000 & 93.4 & 0.933 & 95 & 0.95 & 96.5 & 0.965 \\
\hline
\end{tabular}

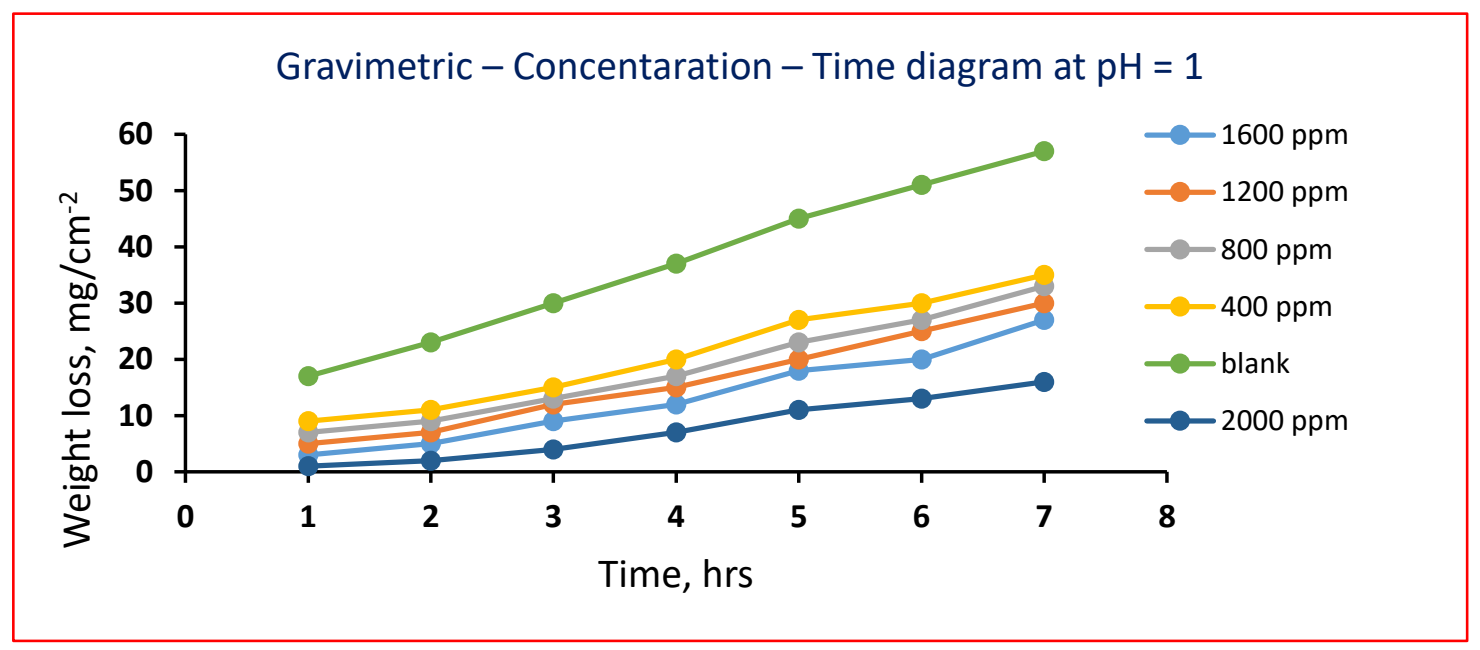

Figure 2. Weight loss of steel as a function in time in $1.0 \mathrm{~N} \mathrm{HCl}$ in the absence and presence of expired drug as a green inhibitor for steel corrosion.

\subsubsection{Effect of temperature}

To elucidate the mechanism of inhibition and determine the kinetic parameters of the corrosion process, gravimetric (weight loss) measurements were performed at different 
temperatures, namely, 303, 313, 323, and $333 \mathrm{~K}$. The effect of temperature on the percentage inhibition efficiency of steel in the presence of the inhibitor is graphically represented in Figure 3. The values of I.E.\% decreased with an increase in temperature, leading to the conclusion that the protective film of these compounds formed on the steel surface is less stable at a higher temperature. This may be due to the desorption of some adsorbed molecules from the steel surface at higher temperatures due to which a greater area of the metal is exposed to the acid environment [26-29]. All the experiments were done in triplicate and the recorded data were taken to the mean value with $( \pm 0.1)$ error [36-45].

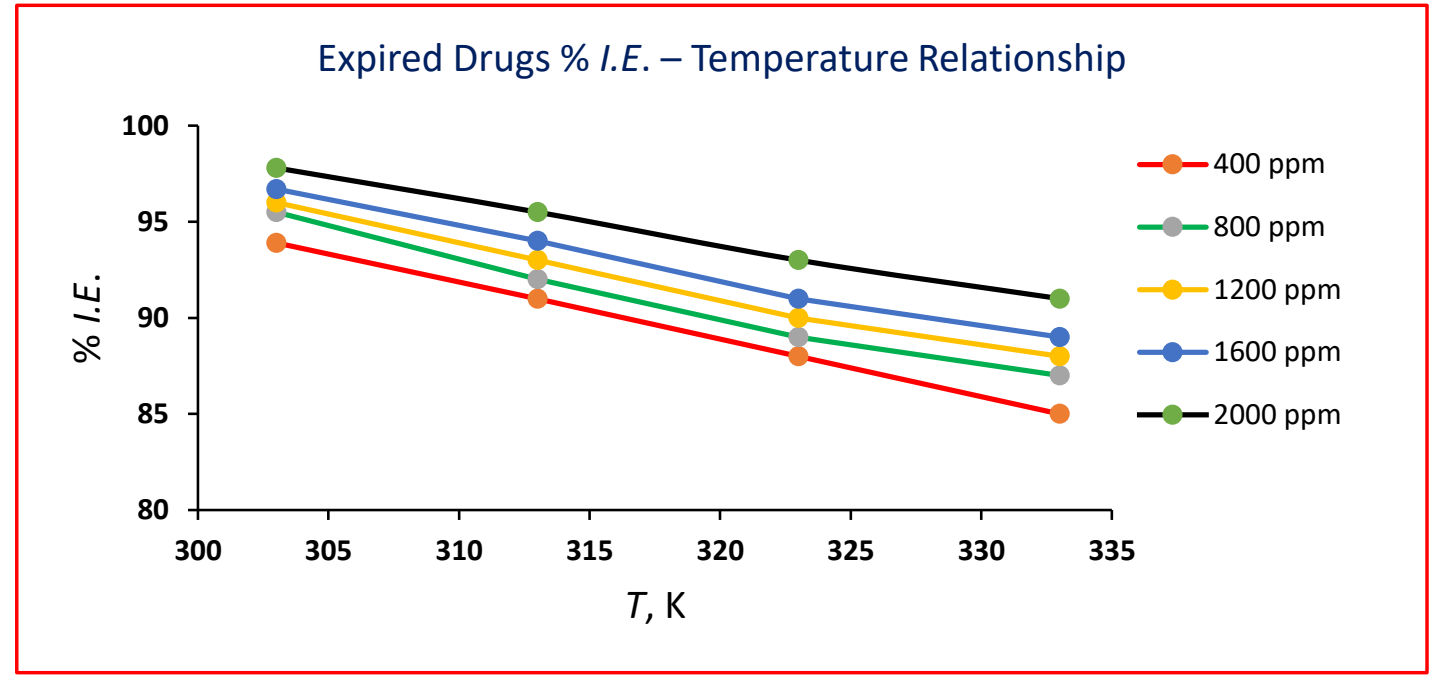

Figure 3. Effect of temperature on I.E.\% of steel in $1.0 \mathrm{~N} \mathrm{HCl}$ in the presence of different concentrations of the expired drug green inhibitor, data from weight loss at $\mathrm{pH}=3$.

The dependence of the corrosion rate on temperature can be expressed by Arrhenius equation and transition state equation [46-50]:

$$
\ln R_{\text {corr. }}=\left(-E_{\mathrm{a}} / R T\right)+A
$$

Where $E_{\mathrm{a}}$ is the apparent activation energy, $R$ is the universal gas constant, $A$ is Arrhenius pre-exponential factor, and $T$ is the absolute temperature. The apparent activation energy can be calculated by linear regression between $\log C . R$. and 1/T. Figure 4 shows the Arrhenius plot for carbon steel immersed in $1.0 \mathrm{M}$ hydrochloric acid in the absence and presence of different drug inhibitor concentrations. The plots obtained are straight lines and the slope of each straight line gives the apparent activation energy. The results are shown in Table 3 . In the present study, the higher value of $E_{\mathrm{a}}$ for carbon steel in the presence of the expired drug inhibitor compared to that in its absence may be attributed to its physical adsorption. The increase in $E_{\mathrm{a}}$ can be attributed to an appreciable decrease in the adsorption of the inhibitor on the carbon steel surface with an increase in temperature and a corresponding increase in corrosion rates occurs because the greater area of the metal remains exposed to the acid environment [26-29]. 
Table 3. Values of activation parameters of carbon steel in $1.0 \mathrm{~N} \mathrm{HCl}$ in the absence and presence of different concentrations of the expired drug inhibitor.

\begin{tabular}{ccc}
\hline Inhibitor & Inhibitor concentration $(\mathbf{p p m})$ & $\boldsymbol{E}_{\mathbf{a}}\left(\mathbf{k J} \cdot \mathbf{m o l}^{\mathbf{- 1}}\right)$ \\
\hline Blank & 0 & 51.63 \\
\hline & 400 & 59.6 \\
Expired Desloratadine drug & 800 & 62.4 \\
& 1200 & 64.3 \\
& 1600 & 65.7 \\
& 2000 & 67.2 \\
\hline
\end{tabular}

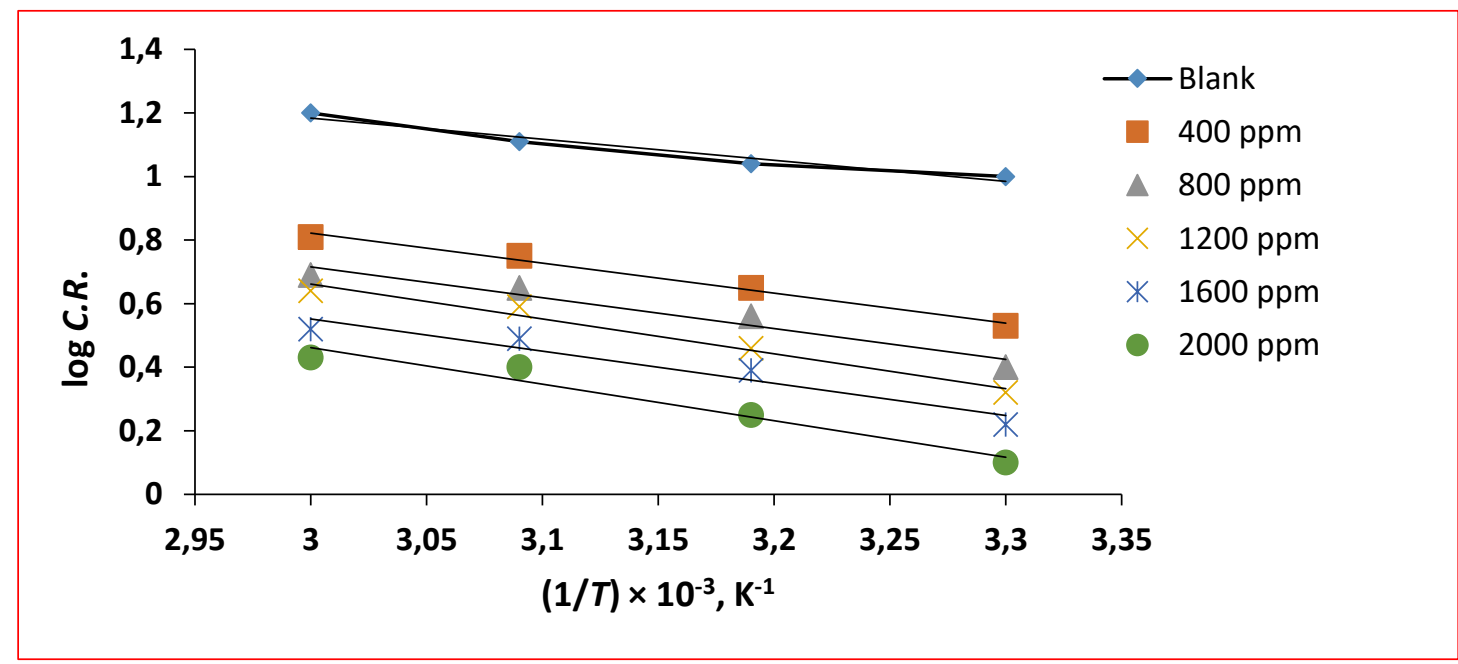

Figure 4. Arrhenius plot for carbon steel in $1.0 \mathrm{~N} \mathrm{HCl}$ solution in the absence and presence of different concentrations of the expired drug inhibitor used.

\subsection{Atomic Absorption Spectroscopy (AAS)}

Atomic absorption spectroscopy (AAS) produces considerable simplification of procedures for the analysis of aqueous, acidic, or basic solutions, and thereby contributes to a reduction in costs. The industrial application of atomic absorption spectroscopy for routine analysis is divided into four areas: (1) incoming inspection of all raw materials, (2) production testing, (3) final inspection of all products, and (4) environmental analysis. For rapid analysis during the production process, atomic absorption is mainly of indirect value because, due to the sequential character of the technique, it cannot be used for complete steel or slag analysis in two to three minutes $[13,42]$. AAS was used for corrosion rate prediction in various media, acidic, basic, and neutral based on fundamental chemistry of the solubility of the corrosion products. The AAS method was applied for the determination of Fe ions in mineral waters and natural waters $[13,42]$. The iron ions released into the solution due to corrosion were detected directly by atomic absorption spectroscopy and their concentration was determined using a calibration curve. The corrosion of iron samples in the solution was accelerated by 
high salinity, lower $\mathrm{pH}$, the presence of chloride ions, and higher temperature [13]. Iron corrosion is a complex process that occurs when iron is exposed to oxygen and humidity and is exacerbated by the presence of chloride ions. The deterioration of iron structures or other components can be costly to society and can be evaluated by following the properties of the corroding material [42]. In the present study, the concentrations of ferrous ions $\mathrm{Fe}^{2+}$ resulting from corrosion of steel by acidic $\mathrm{HCl}$ of different $\mathrm{pH}$ were determined by atomic absorption spectroscopy. The concentrations of ions passed into the solution were measured using AAS to determine the concentrations of ferrous ions within corrosive solution both when the green inhibitor was absent and present. The data of AAS are listed in Table 4 and Figure 5 which shows that the concentration of ferrous ion $\mathrm{Fe}^{2+}$ in the corrosive medium decreased on increasing the inhibitor concentration and increased on lowering the solution $\mathrm{pH}$. Here the concentration of ferrous ions is taken as a function of corrosion rate, hence as the concentration of ferrous ions in the solution increases, the corrosion rate increases and vice versa. The entire process is affected by adding the inhibitor. The data in Table 4 agree well with the results obtained by the gravimetric (weight loss) method, so that the two gravimetric techniques are in good agreement with each other. This observation indicates that addition of expired Desloratadine drug inhibits the corrosion of steel in the acid environment and slows down the iron dissolution process (ferrous ion concentration $\mathrm{Fe}^{2+}$ ) in this environment at lower $\mathrm{pH}$ values.

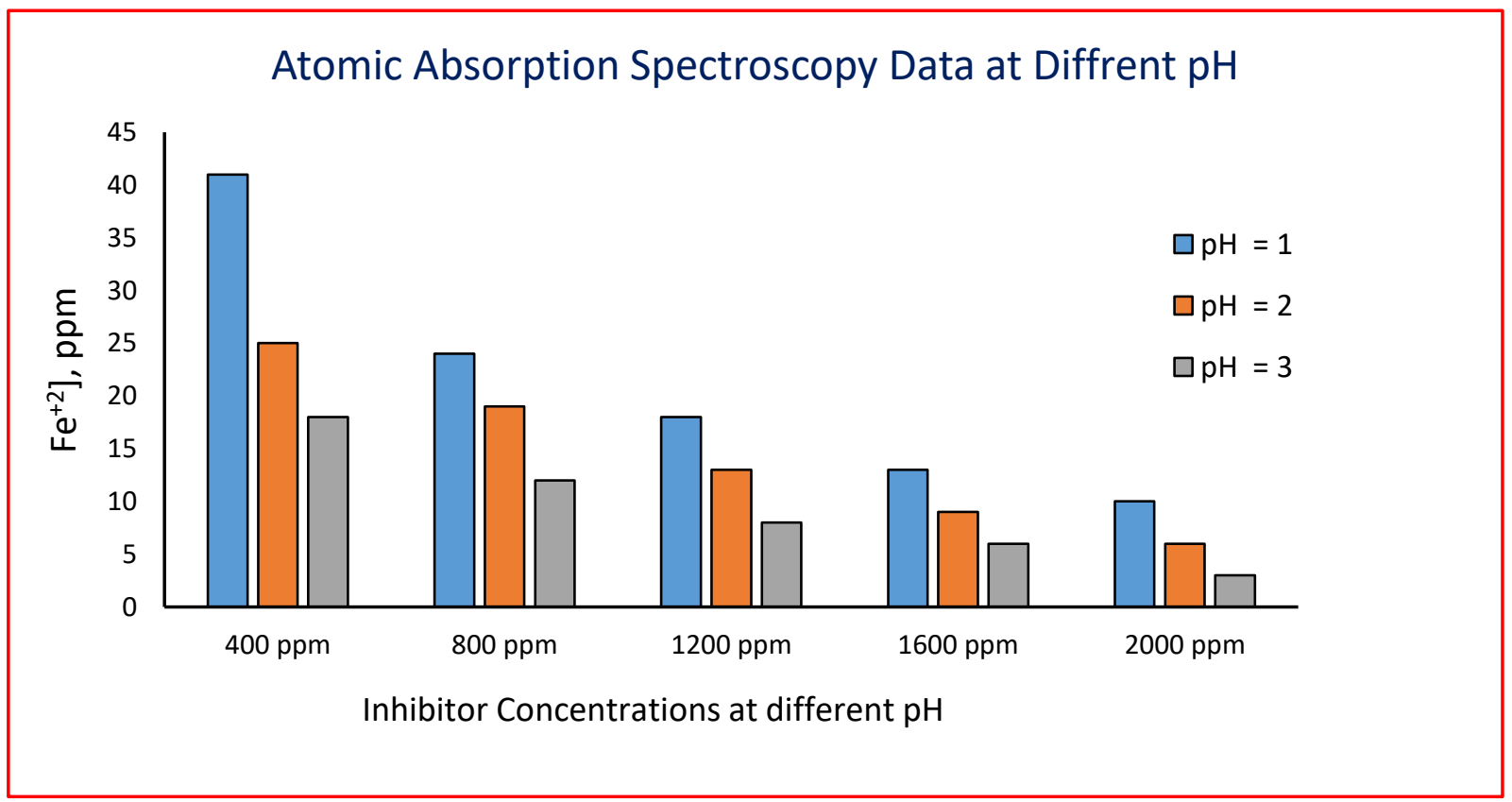

Figure 5. Effect of expired drugs inhibitor concentrations on the ferrous ion concentration $\left[\mathrm{Fe}^{2+}\right]$ in the presence of $1.0 \mathrm{~N} \mathrm{HCl}$, data obtained from atomic Absorption Spectroscopy (AAS) at different $\mathrm{pH}$. 
Table 4. Effect of $\mathrm{pH}$ and inhibitor concentration on ferrous ion concentration as determined by the AAS technique.

\begin{tabular}{ccccc}
\hline \multirow{2}{*}{ Sample } & \multirow{2}{*}{$\begin{array}{c}\text { Inhibitor } \\
\text { concentration, }\end{array}$} & \multicolumn{2}{c}{ Concentration of ferrous ions $\left[\mathbf{F e}^{\mathbf{2 +}}\right], \mathbf{p p m}$} \\
\cline { 3 - 5 } & 0 & $\mathbf{p H}=\mathbf{1}$ & $\mathbf{p H}=\mathbf{2}$ & $\mathbf{p H}=\mathbf{3}$ \\
\hline \multirow{3}{*}{ Expired } & 400 & 131 & 122 & 109 \\
Desloratadine & 800 & 51 & 39 & 31 \\
& 1200 & 40 & 27 & 17 \\
& 1600 & 25 & 21 & 15 \\
& 2000 & 19 & 15 & 13 \\
& & 15 & 12 & 10 \\
\hline
\end{tabular}

\subsection{Gasometrical technique (Hydrogen Evolution Method)}

Table 5. Hydrogen volumes and the percentage inhibition efficiency for the steel corrosion in acid $\mathrm{HCl}$ solution with different $\mathrm{pH}$ with and without different concentrations of the expired drug at room temperature after $7 \mathrm{~h}$.

\begin{tabular}{|c|c|c|c|c|c|c|}
\hline \multirow{2}{*}{$\begin{array}{c}\text { Expired drug } \\
\text { concentration, } \\
\text { ppm }\end{array}$} & \multicolumn{2}{|c|}{$\mathrm{pH}=1$} & \multicolumn{2}{|c|}{$\mathrm{pH}=\mathbf{2}$} & \multicolumn{2}{|c|}{$\mathbf{p H}=\mathbf{3}$} \\
\hline & $\begin{array}{l}\text { Volume of } \\
\text { hydrogen } \\
\left(\mathrm{mL} / \mathrm{cm}^{2}\right)\end{array}$ & I.E.\% & $\begin{array}{l}\text { Volume of } \\
\text { hydrogen } \\
\left(\mathbf{m L} / \mathbf{c m}^{2}\right)\end{array}$ & I.E.\% & $\begin{array}{l}\text { Volume of } \\
\text { hydrogen } \\
\left(\mathrm{mL} / \mathrm{cm}^{2}\right)\end{array}$ & I.E. \% \\
\hline 0 & 56 & - & 49 & - & 38 & - \\
\hline 400 & 13 & 76.8 & 11 & 77.5 & 8 & 79 \\
\hline 800 & 11 & 80.3 & 9 & 81.6 & 6 & 84.2 \\
\hline 1200 & 10 & 82.1 & 8 & 83.7 & 5 & 86.8 \\
\hline 1600 & 7 & 87.5 & 5 & 89.7 & 3.5 & 90.7 \\
\hline 2000 & 6 & 89.3 & 4 & 91.8 & 2.0 & 94.8 \\
\hline
\end{tabular}

The gasometrical technique is based on measuring the evolved hydrogen gas with time in the absence and presence of inhibitors in an acid environment. The gasometrical technique (hydrogen evolution method) was used for evaluation of the expired Desloratadine as a green corrosion inhibitor for carbon steel in an acid hydrochloric acid solution with different low

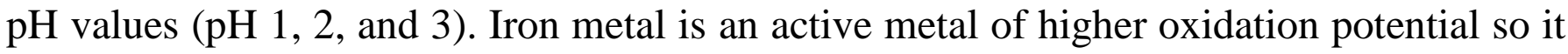
replaces hydrogen from the acid easily giving a metal salt and hydrogen evolved in gaseous form. The volume of hydrogen evolved during the corrosion reaction of iron with acidic $\mathrm{HCl}$ medium in the absence and presence of different concentrations of expired Desloratadine drug as a green inhibitor, 400, 800, 1200, 1600, and 2000 ppm, was measured with time at 
room temperature $\left(30^{\circ} \mathrm{C}\right)$. The inhibition efficiency was calculated using the following equation $[13,17,42]$.

$$
\text { I.E. } \%=\left[1-\left(V_{\text {inh. }} / V_{\text {free }}\right)\right] \cdot 100
$$

where $V_{\text {inh }}$ is the volume of hydrogen gas evolved for the inhibited solution and $V_{\text {free }}$ for the uninhibited solution. The evolved hydrogen volumes and inhibition efficiencies at different concentrations of the green inhibitor, Desloratadine, are shown in Table 5. The inhibition efficiency increases with increasing inhibitor concentration which indicates that the drug compound acts as a good inhibitor for carbon steel in $\mathrm{HCl}$ acid environment [42].

\subsection{Thermometric Measurements}

Reaction number $(R N)$ values are known as a relative measure of retardation of the dissolution process [13]. The extent of corrosion inhibition can be expressed in terms of the percentage reduction in reaction number $(\% R R)$ given by the following equation $[13,26,42]$.

$$
\% R R=\frac{R N_{\text {uninhibited }}-R N_{\text {inhibited }}}{R N_{\text {uninhibited }}} \cdot 100
$$

The thermometric parameters and inhibition efficiency are summarized in Table 6 . The inhibition efficiency and $t_{\mathrm{m}}$ increase with increasing inhibitor concentration. The inhibition efficiency and time delay $\left(\Delta t_{\mathrm{m}}\right)$ of the inhibitor decrease with increasing $\mathrm{pH}$ in the following series: $\mathrm{pH} 3>\mathrm{pH} 2>\mathrm{pH}$ 1. This series is similar to that obtained from both weight loss and gasometrical techniques.

Table 6. Thermometric parameters for the steel corrosion in acidic $\mathrm{HCl}$ solution with different $\mathrm{pH}$ values in the presence of $300 \mathrm{ppm}$ of expired Desloratadine drug as a green inhibitor.

\begin{tabular}{cccc}
\hline $\begin{array}{c}\text { Thermometric } \\
\text { parameters }\end{array}$ & $\begin{array}{c}\mathbf{H C l}, \mathbf{p H}=\mathbf{1} \\
\text { with expired } \\
\text { Desloratadine } \\
\text { inhibitor }\end{array}$ & $\begin{array}{c}\mathbf{H C l}, \mathbf{p H}=\mathbf{2} \\
\text { with expired } \\
\text { Desloratadine } \\
\text { inhibitor }\end{array}$ & $\begin{array}{c}\mathbf{H C l}, \mathbf{p H}=\mathbf{3} \\
\text { with expired } \\
\text { Desloratadine } \\
\text { inhibitor }\end{array}$ \\
\hline$T_{\mathrm{m},}{ }^{\circ} \mathrm{C}$ & 43 & 41 & 38 \\
$t_{\mathrm{m}}, \mathrm{min}$ & 313 & 350 & 365 \\
$R N,{ }^{\circ} \mathrm{C} / \mathrm{min}$ & 0.042 & 0.031 & 0.022 \\
$\% R R$ & 89 & 91 & 94 \\
$\Delta t_{\mathrm{m}}$ & 278 & 321 & 342 \\
\hline
\end{tabular}

\subsection{Acidimetric measurements}

The $\mathrm{pH}$ was checked for the five concentrations 400, 800, 1200, 1600, and $2000 \mathrm{ppm}$ pre and post dipping in the checked solution for $7 \mathrm{~h}$. The $\left[\mathrm{H}^{+}\right]$value was computed in each case. 
The corrosion rate $(W)$ of steel samples was computed utilizing the next equation $[13,26,42]$ :

$$
W\left(\text { mole } \cdot \mathrm{dm}^{-3} \cdot \mathrm{cm}^{-2} \cdot \mathrm{h}^{-1}\right)=\Delta \mathrm{H}^{+} / A t
$$

Where $\left[\Delta \mathrm{H}^{+}\right]$is the difference between the first and last concentration of $\mathrm{H}^{+}, A$ the surface area of the coupon in $\mathrm{cm}^{2}$, and $t$ is the time in $\mathrm{h}$. The I.E.\% was computed utilizing the next equation:

$$
\text { I.E. } \%=1-\left(\left[\Delta \mathrm{H}^{+}\right]_{\text {inh }} /\left[\Delta \mathrm{H}^{+}\right]_{\mathrm{uninh}}\right) \cdot 100
$$

Where $\left[\Delta \mathrm{H}^{+}\right]_{\text {inh }}$ and $\left[\Delta \mathrm{H}^{+}\right]_{\text {uninh }}$ are the difference in $\mathrm{H}^{+}$concentration with and without the Desloratadine green inhibitor, respectively.

The values of surface coverage $(\theta)$ were computed utilizing the next equation [26-29]:

$$
\theta=1-\left(\left[\Delta \mathrm{H}^{+}\right]_{\text {inh }} /\left[\Delta \mathrm{H}^{+}\right]_{\text {uninh }}\right)
$$

As shown in Table 7, the values of corrosion inhibition efficiency and surface coverage increased with increasing concentration of Desloratadine green inhibitor due to a decrease in the hydrogen ion concentration in the medium as the inhibitor molecule acts as a ligand for protons in acidic media.

\begin{tabular}{|c|c|c|c|c|c|c|c|c|c|}
\hline \multirow{2}{*}{$\begin{array}{c}\text { Expired drug } \\
\text { concentration, } \\
\text { ppm }\end{array}$} & \multicolumn{3}{|c|}{$\mathrm{pH}=1$} & \multicolumn{3}{|c|}{$\mathrm{pH}=2$} & \multicolumn{3}{|c|}{$\mathrm{pH}=3$} \\
\hline & $\Delta \mathrm{H}^{+} \cdot 10^{4}$ & $\boldsymbol{\theta}$ & I.E. \% & $\Delta \mathrm{H}^{+} \cdot 10^{4}$ & $\theta$ & I.E.\% & $\Delta \mathbf{H}^{+} \cdot 10^{4}$ & $\theta$ & I.E. $\%$ \\
\hline 0 & 96 & - & - & 89 & - & - & 82 & & \\
\hline 400 ppm & 17 & 0.82 & 82.0 & 13 & 0.85 & 85 & 11 & 0.86 & 86 \\
\hline 800 ppm & 15 & 0.84 & 84.0 & 12 & 0.86 & 86 & 9 & 0.89 & 89 \\
\hline $1200 \mathrm{ppm}$ & 12 & 0.875 & 87.5 & 10 & 0.89 & 89 & 8 & 0.9 & 90 \\
\hline $1600 \mathrm{ppm}$ & 10 & 0.896 & 89.6 & 8 & 0.91 & 91 & 6 & 0.93 & 93 \\
\hline 2000 ppm & 9 & 0.906 & 90.6 & 7 & 0.92 & 92 & 5 & 0.94 & 0.94 \\
\hline
\end{tabular}

Table 7. Values of I.E.\% determined by the acidimetric method for expired Desloratadine inhibitor in $1.0 \mathrm{~N}$ $\mathrm{HCl}$ at $303 \mathrm{~K}$.

\section{Conclusions}

1. Expired Desloratadine drug is considered a green corrosion inhibitor as it is nontoxic to humans, especially at very low concentrations. In addition, prevention of steel corrosion is of environmental importance, as corrosion is a terrible waste of both natural resources and money.

2. The corrosion inhibition efficiency increases with increasing Desloratadine inhibitor concentration and reaches $98 \%$ at 1200 ppm, whereas the $\mathrm{Fe}^{2+}$ ion concentration decreases. 
3. AAS data show that the ferrous ion $\mathrm{Fe}^{2+}$ concentration decreased with increasing inhibitor concentration and increased with a decrease in the solution $\mathrm{pH}$.

4. The volume of hydrogen evolved during the corrosion reaction of steel in acidic $\mathrm{HCl}$ medium decreased with increasing expired Desloratadine inhibitor concentration, which may be due to inhibitor compounds controlling the hydrogen evolution reaction.

5 . The reduction in the reaction number and time delay $\left(\Delta t_{\mathrm{m}}\right)$ of expired Desloratadine inhibitor decrease with increasing $\mathrm{pH}$ in the following series: $\mathrm{pH} 3>\mathrm{pH} 2>\mathrm{pH} 1$.

6 . The acidimetric method results indicate that the hydrogen ion concentration decreased in the inhibited medium as the inhibitor molecules act as a ligand for protons in an acid environment.

7. The data obtained from different analytical techniques are in good agreement with each other within $( \pm 2 \%)$ and indicate that addition of expired Desloratadine drug inhibits the corrosion of steel in an acid environment and decreases the iron dissolution process in this environment. So the expired Desloratadine drug acts as a green corrosion inhibitor.

\section{Acknowledgment}

This research has been funded by Scientific Research Deanship at University of Ha'il - Saudi Arabia through project number RG - 20076. The authors highly appreciates the Scientific Research Deanship at University of Hail, KSA, on continuous support.

\section{References}

1. R.S. Abdel Hameed, Expired Ranitidine drugs as corrosion inhibitor for aluminum in 1M Sulfuric acid, Al-Azhar Bull. Sci., 2009, 20, 151-163. doi: 10.21608/absb.2009.7551

2. R.S. Abdel Hameed, Ranitidine Drugs as Non-Toxic Corrosion Inhibitor for Mild Steel in Sulfuric Acid Medium, Port. Electrochim. Acta, 2011, 29, 273-285. doi: 10.4152/pea.201104273

3. R.S. Abdel Hameed, Expired drugs as corrosion inhibitors for metals and alloys, Phys. Chem.: Indian J., 2013, 8, 146-149.

4. R.S. Abdel Hameed, H.I. Al Shafey and A.H. Abu-Nawwas, 2-(2,6-dichloranilino) phenylacetic acid Drugs as Eco-Friendly Corrosion Inhibitors for Mild Steel in $1 \mathrm{M} \mathrm{HCl}$, Int. J. Electrochem. Sci., 2014, 9, 6006-6019.

5. R.S. Abdel Hameed, H.I. Al Shafey and A.H. Abu-Nawwas, Expired Voltaren Drugs as Corrosion Inhibitor for Aluminium in Sulfuric Acid, Int. J. Electrochem. Sci., 2015, 10, 2098-2109.

6. H.I. Al-Shafey, R.S. Abdel Hameed, F.A. Ali, Abd El-Aleem S. Aboul-Magd and M. Salah, Effect of Expired Drugs as Corrosion Inhibitors for Carbon Steel in 1M HCL Solution, Int. J. Pharm. Sci. Rev. Res., 2014, 27, no. 1, 146-159.

7. N. Vaszilcsin, D.-A. Duca, A. Flueraş and M.-L. Dan, Expired drugs as inhibitors in electrochemical processes - a mini-review, Studia UBB, Chemia, 2019, 64, 17-32. doi: $\underline{10.24193 / \text { subbchem.2019.3.02 }}$ 
8. M. Abdallah, A. Fawzy and A. Al Bahir, The Effect of Expired Acyclovir and Omeprazole Drugs on the Inhibition of Sabic Iron Corrosion in $\mathrm{HCl}$ Solution, Int. J. Electrochem. Sci., 2020, 15, 4739-4753. doi: 10.20964/2020.05.8

9. N.K. Gupta, C.S.A. Gopal, V. Srivastava and M.A. Quraishi, Application of expired drugs in corrosion inhibition of mild steel, Int. J. Pharm. Chem. Anal., 2017, 4, 8-12. doi: $10.18231 / 2394-2797.2017 .0003$

10. R.S. Abdel Hameed, H.I. Al-Shafey, E.A. Ismail, Abd-Alhakeem H. Abu-Nawwas and O.E. El Azabawy, Poly (Oxyethylene)Terphthylamine As Corrosion Inhibitors For Carbon Steel In Methanoic Acid, Int. J. Eng. Res. Appl., 2013, 3, 1094-1103.

11. R.S. Abdel Hameed, H.I. Al-Shafey, A.S. Abul Magd and H.A. Shehata, Pyrazole derivatives as corrosion inhibitor for C-steel in hydrochloric acid medium, J. Mater. Environ. Sci., 2012, 3, no. 2, 294-305.

12. M. Alfakeer, M.Abdallah and R.S. Abdel Hameed, Propoxylated Fatty Esters as Safe Inhibitors for Corrosion of Zinc in Hydrochloric Acid, Prot. Met. Phys. Chem. Surf., 2020, 56, no. 1, 225-232. doi: 10.1134/S2070205120010025

13. R.S. Abdel Hameed, E.H. Aljuhani, R. Felaly and A.M. Munshi, Effect of expired paracetamol- $\mathrm{Zn}^{+2}$ system and its synergistic effect towards iron dissolution inhibition and green inhibition performance, J. Adhes. Sci. Technol., 2020, 34, 838-855. doi: 10.1080/01694243.2020.1826801

14. R.S. Abdel Hameed, E.A. Ismail, H.I. Al-Shafey and Mohamed A. Abbas, Expired Indomethacin Therapeutics as Corrosion Inhibitors for Carbon Steel in $1.0 \mathrm{M}$ Hydrochloric Acid Media, J. Bio- Tribo-Corros., 2020, 6, 114. doi: 10.1007/s40735020-00403-5.

15. R.S. Abdel Hameed and M. Abdallah, Corrosion Inhibition of Carbon Steel in 1M Hydrochloric Acid using some Pyrazolo[3,4-d]Pyrimidnone Derivatives, Prot. Met. Phys. Chem. Surf., 2018, 54, 113-121. doi: 10.1134/S2070205118010239

16. Gh. Golestani, M. Shahidi and D. Ghazanfari, Electrochemical evaluation of antibacterial drugs as environment - friendly inhibitors for corrosion of carbon steel in HCl solution, Appl. Surf. Sci., 2014, 308, 347-362. doi: 10.1016/j.apsusc.2014.04.172

17. R.S. Abdel Hameed, M. Alfakeer and M. Abdallah, Inhibiting Properties of Some Heterocyclic Amide Derivatives as Potential Nontoxic Corrosion Inhibitors for Carbon Steel in 1.0 M Sulfuric Acid, Surf. Eng. Appl. Electrochem., 2018, 54, no. 6, 599-606. doi: $10.3103 /$ S1068375518060054

18. M. Abdallah, A. Fawzy, H. Hawsawi, R.S. Abdel Hameed and Salih S. Al-Juaid, Estimation of Water-Soluble Polymers (Poloxamer and Pectin) as Corrosion Inhibitors for Carbon Steel in Acidic Medium, Int. J. Electrochem. Sci., 2020, 15, 8129-8144. doi: $10.20964 / 2020.08 .73$

19. R.S. Abdel Hameed, H.I. Alshafy and O. Farghaly, Corrosion of mild steel in $\mathrm{NaCl}$ solutions and effect of recycled plastic waste inhibitors, Res. Rev. Electrochem., 2012, 3, no. 2, 41-49. 
20. M. Alfakeer, M. Abdallah and R.S. Abdel Hameed, Propoxylated Fatty Esters as Safe Inhibitors for Corrosion of Zinc in Hydrochloric Acid, Prot. Met. Phys. Chem. Surf., 2020, 56, no. 1, 225-232. doi: 10.1134/S2070205120010025

21. M. Abdallah, F.H. Al-abdali, E.M. Kamar, R. El-Sayed and R.S. Abdel Hameed, Corrosion inhibition of aluminum in $1.0 \mathrm{M} \mathrm{HCl}$ solution by some nonionic surfactant compounds containing five membered heterocyclic moiety, Chem. Data Collect., 2020, 28, 100407. doi: $10.1016 /$ j.cdc. 2020.100407

22. S. Jayakumar, T. Nandakumar, M. Vadivel, C. Thinaharan, Rani P. George and J. Philip, Corrosion inhibition of mild steel in $1 \mathrm{M} \mathrm{HCl}$ using Tamarindus indica extract: electrochemical, surface and spectroscopic studies, J. Adhes. Sci. Technol., 2019, 34, 131. doi: $10.1080 / 01694243.2019 .1681156$

23. A.S. Fouda, M. Abdallah and M. Medhat, Some Schiff base compounds as inhibitors for corrosion of carbon steel in acidic media, Prot. Met. Phys. Chem. Surf., 2012, 48, no. 4, 477-486. doi: 10.1134/S2070205112040053

24. M. Abdallah, B.H. Asghar, I. Zaafarany and M. Sobhi, Synthesis of some aromatic nitro compounds and its applications as inhibitors for corrosion of carbon steel in hydrochloric acid solution, Prot. Met. Phys. Chem. Surf., 2013, 49, 485-491. doi: 10.1134/S2070205113040187

25. R.S. Abdel Hameed, Recycling of the Used Cooking Oils as Corrosion Inhibitors for Carbon Steel in Hydrochloric acid Corrosive Medium, Adv. Appl. Sci. Res., 2016, 7, no. 2, 92-102.

26. R.S. Abdel Hameed, Cationic Surfactant- $\mathrm{Zn}^{+2}$ System as Mixed Corrosion Inhibitors for Carbon Steel in Sodium Chloride Corrosive Medium, Port. Electrochim. Acta, 2018, 36, 271-283. doi: 10.4152/pea.201804271

27. R.S. Abdel Hameed, Schiff' Bases as Corrosion Inhibitor for Aluminum Alloy in Hydrochloric Acid Medium, Tenside, Surfactants, Deterg., 2019, 56, 209-215. doi: $10.3139 / 113.110622$

28. R.S. Abdel Hameed, Solvent Free Glycolysis of Plastic Waste as Green Corrosion Inhibitor for Carbon Steel in Sulfuric Acid, J. New Mater. Electrochem. Syst., 2017, 20, 141-149. doi: $10.14447 /$ jnmes.v20i3.272

29. R.S. Abdel Hameed, Aminolysis of polyethylene terephthalate waste as corrosion inhibitor for carbon steel in $\mathrm{HCl}$ corrosive medium, Adv. Appl. Sci. Res., 2011, 2, no. 3, 483-499.

30. R.S. Abdel Hameed, Recycling of plastic waste as green corrosion inhibitors for steel in different corrosive media, Mater. Sci.: Indian J., 2016, 14, 12, 503-509.

31. V. González-Núñez, A. Valero and J. Mullol, Safety evaluation of desloratadine in allergic rhinitis, Expert Opin. Drug Saf., 2013, 12, 3, 445-453. doi: $10.1517 / 14740338.2013 .788148$

32. A.R. Bilia and M.C. Bergonzi, The G115 standardized ginseng extract: an example for safety, efficacy, and quality of an herbal medicine, J. Ginseng Res., 2020, 44, no. 2, 179193. doi: $\underline{10.1016 / j . j g r .2019 .06 .003}$ 
33. S.O. Adejo, S.G. Yiase, L. Leke, M. Onuche, M.V. Atondo and T.T. Uzah, Corrosion studies of mild steel in sulphuric acid medium by acidimetric method, Int. J. Corros. Scale Inhib., 2019, 8, no. 1, 50-61. doi: 10.17675/2305-6894-2019-8-1-5

34. R.S. Abdel Hameed, E.H. Aljuhani, A.H. Al-Bagawi, A.H. Shamroukh and M. Abdallah, Study of sulfanyl pyridazine derivatives as efficient corrosion inhibitors for carbon steel in $1.0 \mathrm{M} \mathrm{HCl}$ using analytical techniques, Int. J. Corros. Scale Inhib., 2020, 9, no. 2, 623-643. doi: 10.17675/2305-6894-2020-9-2-16

35. E. Malel and D.E. Shalev, Determining the Effect of Environmental Conditions on Iron Corrosion by Atomic Absorption, J. Chem. Educ., 2013, 90, 490494. doi: 10.1021/ed3001107

36. R.S. Abdel Hameed and A.H. Shamroukh, Synthesis, characterization, and evaluation of some acyclic S-nucleosides of pyrazolo[3,4-d]pyrimidine-thiones as corrosion inhibitors for carbon steel in hydrochloric acid, Int. J. Corros. Scale Inhib., 2017, 6, no. 3, 333348. doi: 10.17675/2305-6894-2017-6-3-8

37. A.G. Berezhnaya, V.V. Chernyavina, E.S. Khudoleeva and I.I. Krotkii, Some imidazolines as inhibitors of steel corrosion in hydrochloric acid, Int. J. Corros. Scale Inhib., 2021, 10, no. 4, 1428-1440. doi: 10.17675/2305-6894-2021-10-4-4

38. R.S. Abdel Hameed, N.S. Elmetery, N.F. Alshemary and H.A. Shehata, Recycling of some plastic waste as green corrosion inhibitors for steel in $1 \mathrm{M}$ phosphoric acid, Mater. Sci. J., 2016, 14, no. 11, 417-4250.

39. M.M. Ibrahim, R.S. Abdel Hameed and Abd-Alhakeem H. Abu-Nawwas, Schiff bases and their metal complexes as corrosion inhibitors in acidic media, Org. Chem.: Indian J., 2013, 9, no. 12, 493-499.

40. R.S. Abdel Hameed, M.T. Qureshi and M. Abdallah, Application of Solid Waste for Corrosion Inhibition of Steel in Different Media - A Review, Int. J. Corros. Scale Inhib., 2021, 10, no. 1, 68-79. doi: 10.17675/2305-6894-2021-10-1-4

41. R.S. Abdel Hameed, M.M. Aljohani, A. Bani Essa, A. Khaled, Amr.M. Nassar, M.M. Badr, S.R. Al-Mhyawi and M.S. Soliman, Electrochemical Techniques for Evaluation of Expired Megavit Drugs as Corrosion Inhibitor for Steel in Hydrochloric Acid, Int. J. Electrochem. Sci., 2021, 16, 1-13. doi: 10.20964/2021.04.15

42. R.S. Abdel Hameed and A.M. Al-bonayan, Recycling of Some Water Soluble Drugs for Corrosion Inhibition of Steel Materials: Analytical and Electrochemical Measurements, J. Optoelectron. Biomed. Mater., 2021, 13, no. 2, 45-55. Link

43. A.S Al-Gorair, H. Hawsawi, A. Fawzy, M. Sobhi, A. Alharbi, R.S. Abdel Hameed, S. Abd El Wanees and M. Abdallah, Evaluation of the Anticorrosion and Adsorption Properties of Polyethylene Glycol and Polyvinyl Alcohol for Corrosion of Iron in $1.0 \mathrm{M}$ $\mathrm{NaCl}$ Solution, Int. J. Electrochem. Sci., 2021, 16, 211119. doi: 10.20964/2021.11.03

44. M. Abdallah, A.S. Al-Gorair, A. Fawzy, H. Hawsawi and R.S. Abdel Hameed, Enhancement of adsorption and anticorrosion performance of two polymeric compounds for the corrosion of SABIC carbon steel in hydrochloric acid, J. Adhes. Sci. Technol., 2021. doi: $\underline{10.1080 / 01694243.2021 .1907041}$ 
45. R.S. Abdel Hameed， D. Mohamed， E.H. Aljuhani， M. Abdallah, M.M. Aljohani, S.R. Al-Mhyawi and M.S. Soliman, Application of Expired Co-Amoxiclav Medicinal Drugs for Corrosion Inhibition of Steel Alloy Used in Petroleum Industry in Acid environment, Int. J. Corros. Scale Inhib., 2021, 10, no. 2, 714-731. doi: 10.17675/23056894-2021-10-2-15.

46. Yu.I. Kuznetsov, Triazoles as a class of multifunctional corrosion inhibitors. Review. Part IV. Magnesium alloys, Int. J. Corros. Scale Inhib., 2021, 10, no. 1, 29-53. doi: 10.17675/2305-6894-2021-10-1-2

47. A. Kadhim, A.A. Al-Amiery, R. Alazawi, M.K.S. Al-Ghezi and R.H. Abass, Corrosion inhibitors. A review, Int. J. Corros. Scale Inhib., 2021, 10, no. 1, 54-67. doi: 10.17675/2305-6894-2021-10-1-3

48. S. Bilgiç, Plant Extracts as Corrosion Inhibitors for Mild Steel in HCl Media - Review I, Int. J. Corros. Scale Inhib., 2021, 10, no. 1, 145-175. doi: 10.17675/2305-6894-2021$\underline{10-1-9}$.

49. N. Karki, S. Neupane, Y. Chaudhary, D.K. Gupta and A.P. Yadav, Equisetum hyemale: a new candidate for green corrosion inhibitor family, Int. J. Corros. Scale Inhib., 2021, 10, no. 1, 206-227. doi: 10.17675/2305-6894-2021-10-1-12

50. A.A. Mahmmod, M.K. Mohammed and M.A. Sultan, Phenyltetrazole compounds inhibition influence on mild steel corrosion in acidic solution, Int. J. Corros. Scale Inhib., 2020, 9, no. 4, 1367-1374. doi: 10.17675/2305-6894-2020-9-4-9 